\title{
6. Vorkommen des Tetrodontium Brownianum (Dickson) Schwaegrichen in Japan als neuem Fundgebiet.
}

\author{
Von Yoshiwo Horikawa und Sadazi Iwamasa. \\ Botanisches Institut der Universität zu Hirosima. \\ (Comm. by S. IKeno, M.I.A., Jan. 12, 1940.)
}

Tetrodontium Brownianum (Dickson) Schwaegrichen ist sehr klein, hat vier Peristomzähne und bekleidet in dichtem Wuchs die inneren Wände der aus kalkfreien Felsen bestehenden Höhlen im subalpinen Nadelwalde. Diese Art und var. rigidum (Hedwig) Juratzka sind bisher nur vom europäischem Kontinent (von den Pyrenäen bis Skandinavien) und aus England bekannt; dagegen kommt var. repandum (Funck) Limpricht ausser dem europäischem Kontinent noch ostwärts bis zum Kaukasus und westwärts bis nach Nordamerika vor. Aus diesem Grunde also betrachtet Th. Herzog in seiner ,, Geographie der Moose, S. 115 (1926) “ diese Art als europäisch-atlantisches Element.

Die im Folgenden beschriebenen zahlreichen Exemplare des Tetrodontium Brownianum (Dickson) Schwaegrichen, var. repandum (Funck) Limpricht sammelten wir in den vulkanischen Gebirgsgegenden von Hokkaidô (Yezo) und Honsyu (Hondo) in Japan, also weit östlich von dem Zentralgebiet der Verbreitung dieser Art. Sowohl für Japan als auch für Ostasien ist die Gattung neu; durch diese Tatsache wird die Reichhaltigkeit der Moosflora Japans aufs neue bestätigt. Auch ergibt sich eine neue Parallele zu den nach Bau und eigentümlichem Standort so nahestehenden Laubmoosen Schistostega osmundacea (Dickson) Mohr und Georgia pellucida (Linnaeus) Rabenhorst: auch sie sind nicht nur auf Europa und Nordamerika beschränkt, sondern auch in japanischen Archipel nachgewiesen-Vgl. Y. Horikawa in Nippon Inkwasyokubutu Dukan (Icones Cryptogamae Japonicae) pp. 900-903, Tab. 433, 434 (1939).

Tetrodontium Brownianum (Dickson) Schwaegrichen in Hedwig, Sp. musc. frond., Suppl. II, P. 1, Fase. 2 (1824) p. 102, t. 128 ; P. Bruch, W. P. Schimper und T. Gümbel, Bryol. eur. III (1836-1851), Mon. p. 4, t. 197 ; W. P. Schimper, Syn. musc. eur. 2 ed. (1876) p. 351 ; Paris, Index Bryol. 2 ed. IV, Fasc. 24 (1905) p. 364 ;

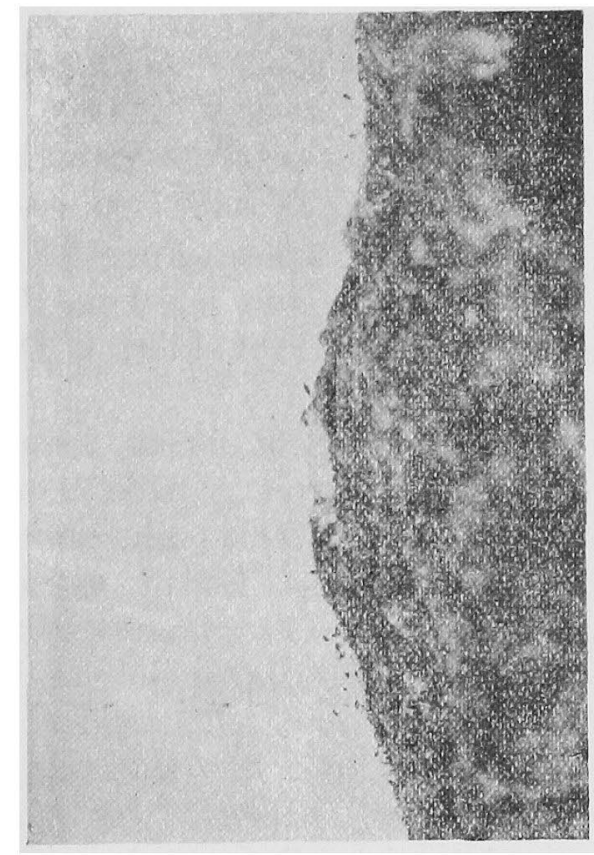

Fig. 1. Natürlicher Habitus des Tetrodontium Brownianum (Dicks.) Schwaegr. var. repandum (Funck) Limpr., in ca. nat. Grösse. Die reifenden Kapseln sind in den Photographie sichtbar. (Photo. auf Berg Kurodake der Daisetugruppe, Juli, 1937.) 


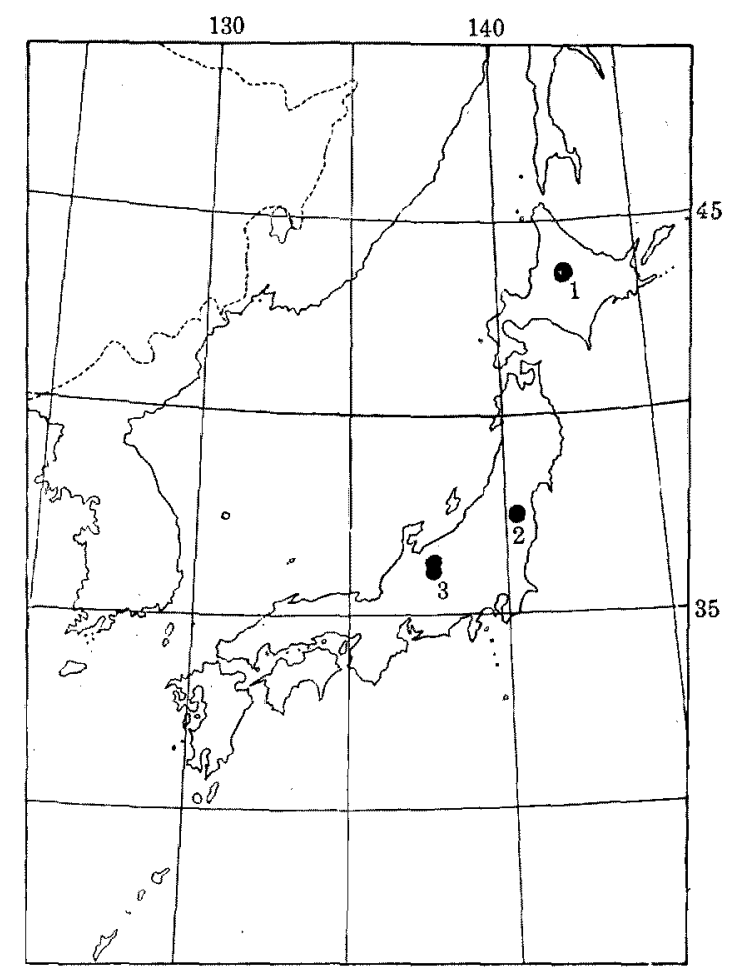

Fig. 2. Fundorte in Japan. 1. Berggruppe des Daisetu.

2. Berg Azuma. 3. Abo-Pass u. Berg Norikura.

Brotherus, Laubm. Fennosk. (1923) p. 221 und in Engler-Prantl, natürl. Pflanzenfam. 2 ed. X (1924) p. 346 ; Herzog, Geographie d. Moose (1926) p. 115 ; Mönkemeyer in Rabenhorst's Krypt.-Flora v. Deutschl., Österr. u. d. Schweiz, IV (1927) p. 412.

var. repandum (Funck) Limpricht, in Kryptfl. v. Schles. I (1876) p. 110 ; Brotherus, Laubm. Fennosk. (1923) p. 221 ; Mönkemeyer in Rabenhorst's Krypt.-Flora v. Deutschl., Österr. u. d. Schweiz, IV (1927) p. 412.

Diözisch. Sehr kleine, gesellige, glanzlose Felsmoose, die im feuchten Zustande hellgrün, in trockenen aber gelbbraun sind. Sterile Pflanzen knospenförmig, mit zahlreichen, braunen Rhizoiden am Grunde des kurzen Stengels. Blätter gerade, eiförmig bis lanzettlich-eiförmig, 0.3$0.6 \mathrm{~mm}$ lang, $0.2 \mathrm{~mm}$ breit, allmählich zugespitzt, ganzrandig, hohl, ohne oder mit undeutlicher, kurzer Rippe; Zellen rundlich oder länglich, 8$10 \times 14-26 \mu$ in der Blattspitze, verlängert, $10-14 \times 30-40 \mu$ in der Mitte, dickwandig und die Kutikula glatt. Protonemablätter zahlreich und herdenweise, aufrecht bis aufsteigend, linear-lanzettlich bis schmal spatelförmig, $0.7-1 \mathrm{~mm}$ lang, $0.06-0.1 \mathrm{~mm}$ breit, zugespitzt oder rund mit 2-3 Zellen hoher und 1-2 reihiger Spitze, ganzrandig, zweiund mehrschichtig mit Ausnahme von einschichtiger Rändern. Dreireihig beblätterte Seitensprosse zahlreich, gestreckt oder aufsteigend, 1.5-2 mm lang; deren Blätter schmal lanzettlich, gespitzt, ganzrandig. Perichätialblätter aufrecht, anliegend, länger als Stengelblätter, ovallanzettlich, 0.9-1.2 mm lang, 0.3-0.5 mm breit, gespitzt, oberwärts feingesägt aber unterwärts ganzrandig, Rippe einfach, fünf Sechstel bis 
ein Drittel des Blattes, oder oft fehlend. Vaginula walzenförmig, mit zahlreichen Paraphysen und unreifen Archegonien besetzt. Seta lang hervorstehend, aufrecht, gerade, zuweilen bogenförmig, oben links gedreht, 3,5-7.5 mm (gewöhnlich 5-6 mm) lang, $0.1 \mathrm{~mm}$ im Durchmesser, gelblich bis fahlgelb, glatt. Kapsel aufrecht, oval oder länglich-oval,
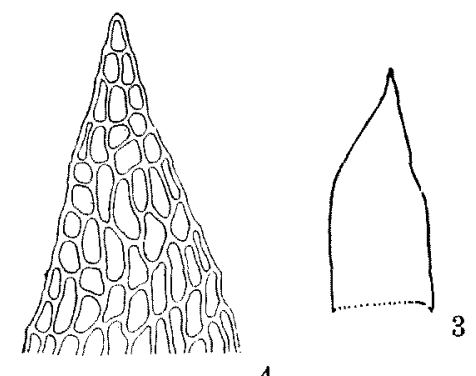

4
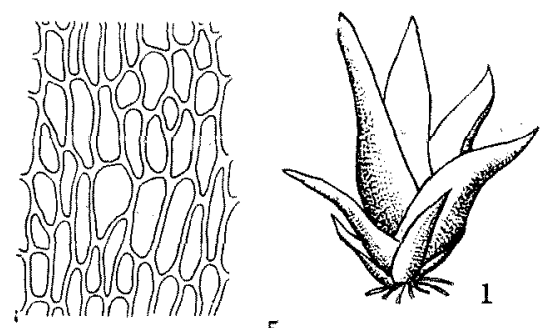

5
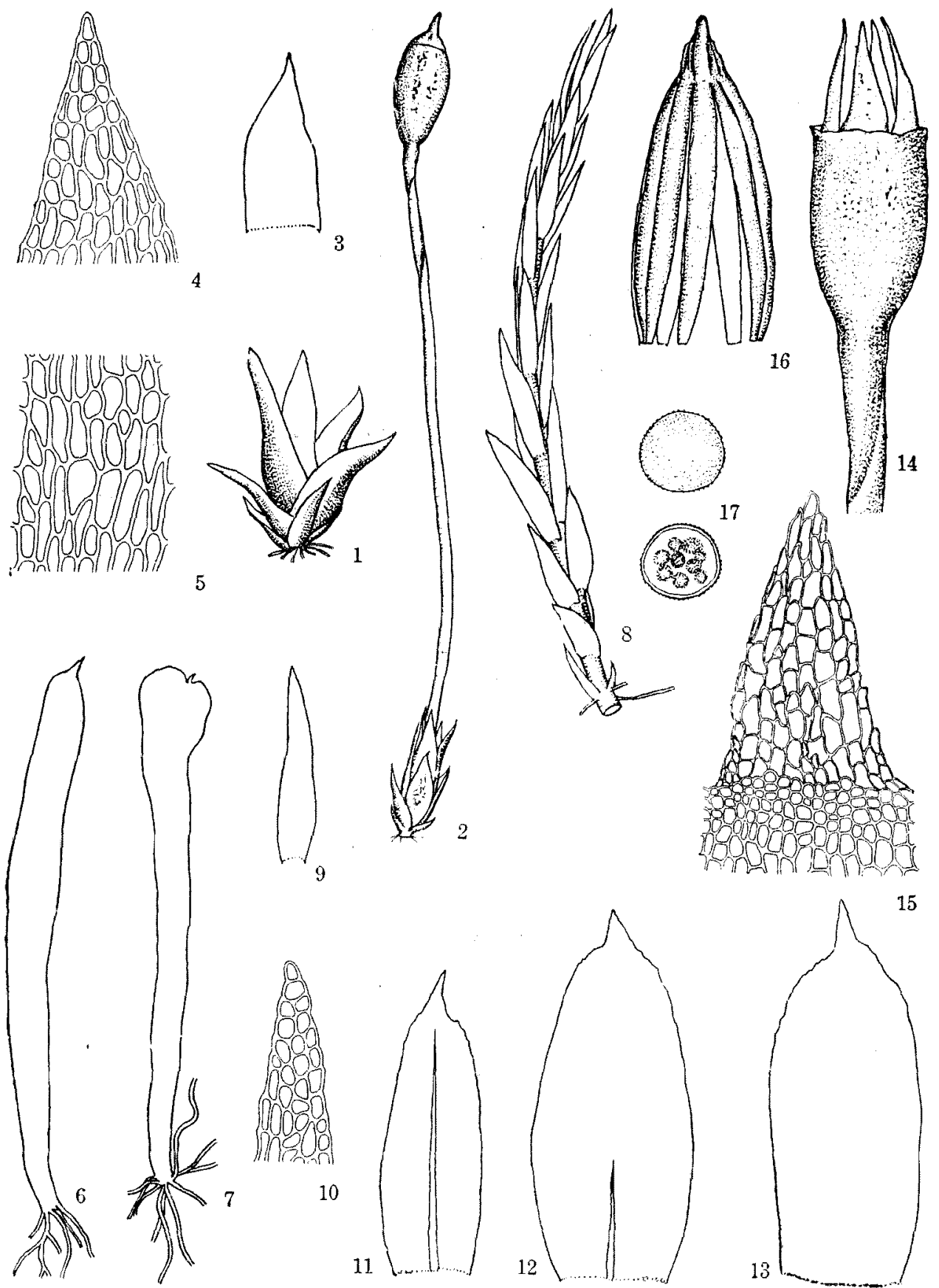

14

Fig. 3. Tetrodontium Brownianum (Dicks.) Schwaegr. var. repandum (Funck) Limpr. 1. Sterile Pflanze, $\times 21$. 2. Fruchtende Pflanze, $\times 14$. 3. Stengelblatt, $\times 39$. 4. Blattspitze, $\times 200$. 5. Zellen aus Blattmitte, $\times 200$. 6, 7. Protonemablätter, $\times 63$. 8. Seitenspross, $\times 39$. 9. Blatt desselben, $\times 63$. 10. Dessen Spitze, $\times 200$. 11, 12, 13. Innerste Perichätialblätter, $\times 39$. 14. Kapsel, $\times 39.15$. Peristomzahn, $\times 118$. 16. Haube, $\times 30$. 17. Sporen, $\times 720$. 
symmetrisch, $0.8-1 \mathrm{~mm}$ lang, $0.5-0.6 \mathrm{~mm}$ im Durchmesser, tiefbraun, glatt. Peristom aus vier Zähnen gebildet, der Zahn dreiseitig-pyramidenfömig, $0.13-0.22 \mathrm{~mm}$ breit an der Basis, $0.24-0.36 \mathrm{~mm}$ hoch, ockergelb; Oberfläche rauh durch nicht ganz regelmässig verteilte, kurze papillenartige Fortsätze. Deckel kegelförmig, an der Basis $0.3-0.4 \mathrm{~mm}$ im Durchmesser, geschnäbelt, $0.3 \mathrm{~mm}$ hoch, gelbbraun bis braun, glatt. Haube glockenförmig, ohne Haare, gelblich, die ganze Kapsel einhüllend, 6-8 mals tief geschlitzt. Sporen kugelförmig, grüngelblich bis gelbbräunlich, $12-16 \mu$ im Durchmesser, feinwarzig und mit Chlorophyllkörnen.

Hab. Hokkaidô: Prov. Isikari, Berg Kurodake der Daisetugruppe, ca. $970 \mathrm{~m}$, Pyroxen-Andesit (Y. Horikawa, Juli, 1937).

Honsyu: Prov. Iwasiro, Berg Azuma, ca. 1700-1750 m, PyroxenAndesit (H. Suzuki, Juli, 1939) ; Prov. Sinano, Abo-Pass, ca. $1800 \mathrm{~m}$, Hornblende- od. Pyroxen-Andesit (S. Iwamasa, Juli, 1935) und Berg Norikura, ca. $2100 \mathrm{~m}$, Hornblende- od. Pyroxen-Andesit (S. Iwamasa, Juli, 1935). 